\title{
TINJAUAN ATAS ANALISIS PROSEDUR PEMBERIAN KREDIT KONSUMTIF PADA PT. BPR PADMA CABANG SINGARAJA
}

\author{
Kadek Rika Sastari \\ Jurusan Akuntansi Program Diploma III, \\ Universitas Pendidikan Ganesha, Singaraja \\ rikasastari@yahoo.com
}

\begin{abstract}
ABSTRAK
Penelitian ini bertujuan untuk mengetahui prosedur pemberian kredit konsumtif pada PT. BPR Padma Cabang Singaraja. Subyek penelitian ini adalah Pt. BPR Padma Cabang Singaraja, dan obyek penelitian ini adalah tinjauan atas analisis prosedur pemberian kredit konsumtif. Metode pengumpulan data yang digunakan dalam penelitian ini adalah metode wawancara dan metode dokumentasi. Data dianalisis dengan menggunakan teknik deskritif kualitatif. Hasil penelitian ini menunjukkan prosedur pemberian kredit konsumtif pada PT. BPR Padma Cabang Singaraja sudah sesuai dengan teori yang ada. Dalam hal ini PT. BPR Padma Cabang Singaraja menetapkan beberapa syarat yang harus dipenuhi oleh calon debitur sesuai dengan ketentuan yang berlaku, serta terdapat beberapa tahapan dalam pemberian kredit konsumtif yaitu; pengajuan permohonan kredit konsumtif, wawancara, on the spot, penganalisaan kredit, keputusan kredit, penandatanganan akad kredit, dan realisasi kredit.
\end{abstract}

Kata kunci : Prosedur Pemberian Kredit Konsumtif.

\begin{abstract}
This research aims to know the procedure the provision of credit consumptive in PT. BPR Padma Cabang Singaraja. The subject of this research is PT. BPR Padma Cabang Singaraja, and object of this research is a review of analysis procedure the provision of credit consumption. Data collection method used in this research is the method interview and methods documentation. Data analyzed by using a technique deskritif qualitative. This research result indicates procedure the provision of credit consumtptive in PT. BPR Padma Cabang Singaraja is in line whit the theory that is. In this case PT. BPR Padma Cabang Singaraja set several requirementsto be protected by the prospective debtors based on regulation, and there are some stage in the provision of credit consumptive namely the request credit consumption, interview, on the spot, credit analysis, credit decision, the signing of do not credit, and realization credit.
\end{abstract}

Keywords : Procedure the provision of credit consumption. 


\section{Pendahuluan}

Pembangunan perekonomian dalam suatu negara di samping memerlukan program pembangunan yang terarah dan terencana untuk mencapai sasaran pembangunan, faktor lain yang dibutuhkan adalah modal atau dana pembangunan yang cukup besar. Maka dari itu diperlukannya mobilitas dana dari masyarakat. Salah satu lembaga yang berperan dalam hal ini adalah lembaga keuangan, karena lembaga keuangan memiliki peran yang besar dalam penyediaan dana untuk kegiatan usaha. Lembaga keuangan adalah setiap perusahaan yang bergerak di bidang keuangan dalam artian kegiatan yang dilakukan di bidang keuangan. Lembaga keuangan dapat digolongkan menjadi dua yaitu Lembaga Keuangan Bank dan Lembaga Keuangan Non Bank.

Bank merupakan badan usaha yang menghimpun dana dari masyarakat dalam bentuk simpanan dan menyalurkannya kepada masyarakat dalam bentuk kredit atau bentukbentuk lainnya dalam rangka meningkatkan taraf hidup rakyat banyak. Bank ada dua jenis yaitu Bank Umum dan BPR. Bank Umum adalah bank yang memberikan jasa yang sifatnya umum, yang artinya memberikan seluruh jasa perbankan yang ada. Sedangkan BPR adalah bank yang kegiatannya hanya menerima simpanan berupa tabungan dan deposito serta menyalurkannya dalam bentuk kredit atau pinjaman. Jadi kegiatan BPR jauh lebih sempit dibandingkan dengan bank umum.

Dalam prakteknya bank juga mamiliki fungsi sebagai lembaga perantara keuangan antara masyarakat yang kelebihan dana dengan masyarakat yang kekurangan dana. Masyarakat yang kelebihan dana maksudnya adalah masyarakat yang memiliki dana yang berlebih kemudian disimpan di bank. Penyimpanan uang di bank disamping aman juga menghasilkan bunga dari uang yang disimpannya. Oleh bank dana simpanan masyarakat ini disalurkan kembali kepada masyarakat yang kekurangan dana atau membutuhkan dana. Bagi masyarakat yang kekurangan dana atau membutuhkan dana untuk membiayai suatu usaha atau kebutuhan rumah tangga mereka dapat menggunakan pinjaman dalam bentuk kredit.

Kredit merupakan penyerahan barang, jasa, atau uang dari satu pihak (kreditur atau pemberi pinjaman) atas dasar kepercayaan kepada pihak lain (nasabah atau pengutang) dengan janji membayar dari penerimaan kredit kepada pemberi kredit pada tanggal yang telah disepakati kedua belah pihak. Kredit yang akan diberikan oleh suatu lembaga keuangan didasarkan atas kepercayaan lembaga keuangan (kreditur) terhadap debitur (nasabah), ini berarti suatu lembaga keuangan baru akan memberikan pinjaman jika suatu lembaga keuangan telah yakin kalua debitur akan mengembalikan pinjaman yang diterimanya sesuai dengan jangka waktu dan syarat yang disepakati.

PT. BPR Padma Cabang Singaraja didirikan untuk membantu dan mendorong pertumbuhan perekonomian dan pembangunan daerah di segala bidang. Sebagai perusahaan yang usahanya bergerak di bidang jasa keuangan, PT. BPR Padma Cabang Singaraja selalu berupaya untuk memberikan pelayanan yang terbaik kepada nasabahnya dengan menyediakan berbagai macam bentuk simpanan dan kredit. Kredit yang disalurkan oleh PT BPR Padma Cabang Singaraja terdiri dari kredit modal kerja, krdit investasi, kredit konsumtif, dan KPR.

Dalam pemberian kredit atau penyaluran kredit kepada penerima kredit (debitur) atau dalam hal ini adalah nasabah. PT BPR Padma Cabang Singaraja selaku kreditur wajib melaksanakan prinsip kehati-hatian dan harus benar-benar menganalisa calon debitur agar menghindari resiko yang lebih besar dikemudian hari, seperti adanya kredit macet. Dengan demikian pemberian kredit pda PT. BPR Padma Cabang Singaraja harus didasarkan pada prosedur pemberian kredit yang sehat dan benar.

Berdasarkan pemaparan dari latar belakang diatas, penulis tertarik untuk melakukan penelitian lebih lanjut terhadap prosedur pemberian kredit konsumtif pada PT. BPR Padma Cabang Singaraja dengan judul "Tinjauan Atas Analisis Prosedur Pemberian Kredit Konsumtif pada PT. BPR Padma Cabang Singarja".

Berdasarkan latar belakang tersebut maka yang menjadi permasalahan dari penelitian ini adalah, bagaimana prosedur pemberian kredit konsumtif pada PT. BPR Padma 
Cabang Singaraja. Dan penelitian ini bertujuan untuk mengetaui prosedur pemberian kredit konsumtif pada PT. BPR Padma Cabang Singaraja.

\section{Metode Penelitian}

Penelitian ini menggunakan analisis deskriptif kualitatif yaitu analisis yang tidak menggunakan perhitungan statistika dan dilakukan dengan cara menganalisis data yang sudah ada kemudian diolah menjadi sebuah teori. Melalui analisis ini diharapkan dapat mengetahui Prosedur Pemberian Kredit Konsumtif pada PT BPR Padma Cabang Singaraja. Agar tujuan penelitian ini dapat tercapai, maka peneliti melakukan pengumpulan data dengan metode wawancara dan dokumentasi.

Penelitian ini dilakukan di PT BPR Padma Cabang Singaraja yang beralamat di Jalan Gajah Mada No 115 Singaraja. Subjek penelitian ini adalah PT BPR Padma Cabang Singaraja dan objek dari penelitian ini adalah Tinjauan atas Analisis Prosedur Pemberian Kredit Konsumtif pada PT BPR Padma Cabang Singaraja. Dari analisis yang dilakukan dapa ditarik kesimpulan mengenai prosedur pemberian kredit konsumtif pada PT. BPR Padma Cabang Singaraja.

\section{Hasil dan Penelitian Hasil Penelitian}

Berdasarkan hasil penelitian pada PT. BPR Padma Cabang Singaraja, dalam prosedur pemberian kredit konsumtif terdapat beberapa tahapan yang harus ditempuh oleh calon debitur mulai dari pengajuan permohonan untuk mendapatkan kredit sampai dengan tahap pencairan kredit. Berikut adalah prosedur pemberian kredit konsumtif yang berlaku pada PT. BPR Padma Cabang Singaraja:

1. Calon Debitur Mendatangi Bank

Calon debitur mendatangi bank untuk mendapatkan informasi kemungkinan mendapatkan kredit. Kemudian bagian pihak bank memberikan penjelasan tentang persyaratan yang harus dipenuhi oleh calon debitur seperti:

1) Foto copy KTP suami dan istri

2) Foto copy Kartu Keluarga dan Akta perkawinan

3) Foto copy NPWP (jika ada)

4) Foto copy BPKB dan STNK masih berlaku

5) Foto copy Sertifikat

6) Foto copy buku tabungan mutasi tiga bulan terakhir

7) Foto copy pembukuan usaha (untuk wiraswasta)

8) Foto copy SIUP, TDP (untuk wiraswasta)

9) Slip gaji 3 bulan terakhir (untuk PNS dan karya swasta)

10) Bukti pembayaran listrik dan air

Setelah itu maka pihak bank memberikan Formulir Permohonan Kredit (FPK) untuk diisi oleh calon debitur.

2. Wawancara

Setelah calon debitur melengkapi semua persyaratan kredit konsumtif maka calon debitur datang kembali ke bank untuk diperiksa mengenai kelengkapannya. Apabila kelengkapan dari calon debitur telah memenuhi persyaratan maka pihak bank akan melakukan wawancara dengan calon debitur. Tujuan diadakannya wawancara adalah untuk mendapatkan informasi mengenai keadaan calon debitur sebagai bahan pertimbangan antara keterangan pada FPK dengan hasil wawancara.

3. On The Spot

Pihak bank melakukan on the spot atau survey langsung kelapangan. Dalam kegiatan ini pihak bank akan melakukan pemeriksaan kelapangan dengan meninjau berbagai objek yang akan dijadikan usaha dan jaminan oleh calon debitur. Kemudian hasil survey tersebut akan dicocokan denga hasil wawancara.

4. Analisa Kredit 
Penganalisaan kredit merupakan kegiatan perbaikan berkas, apabila terdapat kekurangan-kekurangan pada saat setelah dilakukan on the spot di lapangan. Dan hasil dari analisa tersebut akan dibuatkan memorandum analisis kredit.

5. Keputusan Kredit

Keputusan kredit akan menentukan apakah kredit tersebut akan diterima atau ditolak. Apabila diterima maka administrasinya akan disiapkan. Biasanya keputusan kredit mencakup jumlah uang yang diterima, jangka waktu krredit, dan biaya-biaya yang harus dibayar oleh calon debitur. Dan bagi kredit yang ditolak maka akan dikirim surat penolakan dengan alasannya masing-masing.

6. Penandatanganan Akad Kredit

Kegiatan ini merupakan kelanjutan dari keputusan kredit. Sebelum kredit dicairkan terlebih dahulu nasabah harus menandatangani akad kredit, mengikat jaminan dengan surat perjanjian kredit. Penandatanganan dilakukan antara bank dengan debitur secara langsung dan dengan melalui notaris.

7. Realisasi Kredit

Realisasi kredit diberikan setelah penandatanganan akad kredit atau surat-surat yang diperlukan dengan membuka rekening dan tabungan di PT. BPR Padma Cabang Singaraja.

\section{Simpulan dan Saran}

Berdasarkan hasil penelitian dan pembahasan yang telah diuraikan pada bab sebelumnya, maka dapat diambil kesimpulan bahwa prosedur pemberian kredit konsumtif pada PT. BPR Padma Cabang Singaraja sudah sesuai dengan teori yang ada. Dalam hal ini PT. BPR Padma Cabang Singaraja menetapkan beberapa tahap dalam pemberian kredit yang meliputi tahap permohonan kredit dan calon debitur mengajukan berkas persyaratan dari kredit konsumtif, wawancara, on the spot, analisa kredit, keputusan kredit, penandatanganan akad kredit, dan realisasi kredit. Namun, dalam pelaksanaannya masih terdapat beberapa bagian tertentu perlu diadakan perbaikan. Sehingga, proses penyelenggaraan prosedur pemberian kredit konsumtif pada PT. BPR Padma Cabang Singaraja dapat terealisasi dengan lebih baik.Setelah mengetahui prosedur pemberian kredit konsumtif pada PT. BPR Padma Singaraja, maka saran yang dapat diberikan oleh penulis yang mungkin dapat memberikan manfaat untuk meningkatkan efektivitas pelaksanaan prosedur pemberian kredit seperti (1) Bagian kredit harus selektif dalam memilih calon debitur dengan menggunakan penilaian kredit yang telah mempertimbangkan kelayakan kredit. Selektif dalam memilih calon debitur juga dapat mengurangi tingkat kredit bermasalah atau kredit macet; (2) Sebaiknya dilakukan pemisahan fungsi permohonan kredit dan fungsi analisa kredit. Dengan pemisahan ini diharapkan dapat membantu bagian kredit dalam mengevaluasi permohonan kredit dari calon debitur, dalam bentuk laporan, sebelum kredit tersebut diotorisasi (3) Surat perjanjian kredit akan lebih baik jika dibuat rangkap dua. Lembar pertama diarsip oleh notaris dan lembar kedua diarsip oleh Bank.

\section{DAFTAR PUSTAKA}

Bastian, Indra. 2006. Akuntansi Perbankan. Edisi Kedua. Jakarta: Salemba Empat.

Christianto, Ivo Adi. 2013. Prosedur Pemberian Kredit dan Upaya untuk Mengatasi Kredit Macet pada Koperasi Kredit Swastiastu Singaraja. Singaraja: Akuntansi Program Diploma III Fakultas Ekonomi dan Bisnis UNDIKSHA.

Firdaus, Rachmat \& Ariyanti, Maya. 2011. Manajemen Perkreditan Bank Umum: Teori, Masalah Kebijakan dan Aplikasinya. Cetakan Kelima. Bandung: Alfabeta.

Ismail. 2010. Manajemen Perbankan dari Teori Menuju Aplikasi. Jakarta: PT Kencana. 
Kasmir. 2007. Bank dan Lembaga Keuangan Lain. Jakarta: Pernada Media.

Lapoliwa, N. dan Daniel Kuswandi. (2000). Akuntansi Perbankan. Jakarta: Institut Bankir Indonesia.

Marbun. 2003. Kamus Manajemen. Jakarta: Pustaka Sinar Harapan.

Martiana, L Vina Maya. 2013. Tinjauan atas Analisis Prosedur serta Pencatatan Auntansi Kredit Pensiun pada PT. Bank Jabar Banten KCP. IPDN Jatinangor Kab. Sumedang. Bandung: Diploma III Jurusan Akuntansi Fakultas Ekonomi Universitas Widyatama.

Maryati. 2008. Manajemen Perkantoran Efektif. Yogyakarta: Unit Penerbit dan Percetakan Sekolah Tinggi Ilmu Manajemen YKPN.

Moekijat. 1990. Kamus Manajemen. Bandung: Mandar Maju.

Mulyadi. 2010. Sistem Akuntansi. Edisi ke-5. Jakarta : Salemba Empat.

Rahardja, Prathama. 2000. Uang \& Perbankan. Jakarta : Rineka Cipta.

Sastradipoera, komaruddin, 2004. Strategi Manajemen Bisnis Perbankan: Konsep dan Inplementasi Untuk Bersaing. Bandung: Kappa Sigma.

Sinugan, Murchdarsyah. 2000. Managemen Dana Bank. Jakarta: Bumi Aksara.

Sugiyono. 2009. Metode Penelitian Kuantitatif Kualitatif dan $R \& D$. Jakarta: Alfabatis.

Sri Susilo, Sigit Triandaru dan A. Totok Budi Santoso. 2005. Bank dan Lembaga Keuangan. Jakarta : Salemba Empat.

Suyatno, Thomas. 2007. Dasar-dasar Perkreditan. Jakarta: PT Gramedia Pustaka Utama.

Taswan. 2008. Akuntansi Perbankan. Jakarta : Salemba Empat.

Tim Penyusun Kamus Pusat Pembinaan dan Pengembangan Bahasa Departemen Pendidikan dan Kebudayaan. 1996. Kamus Besar Bahasa Indonesia. Jakarta: Balai Pustaka.

Undang-Undang Nomor 10 Tahun 1998 tentang Perbankan . 2002. Jakarta : Diperbanyak oleh PT Raja Grafindo Persada.

Wulandari, Kadek Rina. 2014. Analisis Sistem dan Prosedur Pemberian Kredit Multi Guna (KMG) dalam Upaya Meningkatkan Pengendalian Kredit pada PT. Bank Pembanguna Daerah Bali Cabang Singaraja. Singaraja: Akuntansi Program Diploma III Fakultas Ekonomi dan Bisnis UNDIKSHA. 